\title{
"In different shades of purple": effects of different concentrations of commercial black chokeberry fruit extract [Aronia melanocarpa (Michx) Elliott] on fitness components and wing morphology of the fruit fly, Drosophila melanogaster Meigen, $1830^{1}$
}

\author{
"Mor rengin farklı tonlarında": ticari konsantrasyondaki farklı siyah chokeberry meyve özütü \\ konsantrasyonlarının [Aronia melanocarpa (Michx) Elliott] meyve sineği Drosophila \\ melanogaster Meigen, 1830'in hareket özelliği bileşenleri ve kanat morfolojisi üzerindeki etkileri \\ Tatjana SAVIĆ ${ }^{*}$ \\ Nataša BAJALOVIĆ 5 \\ Slobodan MAKAROV 4 \\ Gordana RADIVOJEVIĆ 3 \\ Luka LUČIĆ $4 \quad$ Dragana MILIČIĆ $4 \quad$ Vladimir TOMIĆ 4 \\ Sonja DULETIĆ-LAUŠEVIĆ 4 \\ Jelena TRAJKOVIĆ ${ }^{4}$ \\ Sofija PAVKOVIĆ-LUČIĆ ${ }^{4}$
}

\begin{abstract}
It is now widely accepted that bioactive compounds of fruits and vegetables reduce oxidative stress, thus having the beneficial effect of decreasing the risk of many human diseases. The aim of this in vivo study was to evaluate the possible protective effects of Aronia melanocarpa (Michx) Elliott fruit extract using Drosophila melanogaster Meigen, 1830 larvae. Study was done in the year 2016, in Department of Genetics of Populations and Ecogenotoxicology at the Institute for Biological Research, University of Belgrade. Simultaneously with treatments, co-treatments with the same concentrations of black chokeberry fruit extract mixed with a methyl methanesulfonate (MMS) were performed. Fitness traits and morphological characters were monitored. Flies fed on undiluted fruit extract, on MMS + undiluted fruit extract and on MMS, exhibited a prolonged developmental time, lower viability and negatively-impacted wing development. Positive biological effects were observed in flies that developed on substrates with 2 and $25 \% \mathrm{~A}$. melanocarpa extract. Only a mixture of MMS $+25 \%$ fruit extract showed positive effects on both fitness components and wing development in comparison with other MMS co-treatments, indicating the ability of this concentration to protect the cells from MMS-induced damage.

Keywords: developmental time, dynamic of eclosion, methyl methanesulfonate, viability, wing shape, wing size

\section{Öz}

Son yıllarda, meyve ve sebzelerin içindeki biyoaktif bileşiklerin oksidatif stresi düşürdüğü, böylece birçok insan hastalığının riskini azaltan faydalı bir etkiye sahip olduğu yaygın olarak kabul edilmektedir. Mevcut in vivo çalışmanın amacı Drosophila melanogaster Meigen, 1830 larvası kullanılarak Aronia melanocarpa (Michx) Elliott'nın meyve özütünün muhtemel koruyucu etkilerini değerlendirmektir. Çalışma 2016 yılında, Belgrad Üniversitesi, Biyolojik Araştırma Enstitüsü'ndeki, Popülasyon Genetiği ve Ekogenotoksikoloji Bölümü’nde gerçekleştirilmiştir. Uygulamalar ile aynı anda, metil metansülfonat (MMS) ile karışıııılmış aynı konsantrasyondaki siyah chokeberry meyve özütüyle yan uygulamalar yapılmıştır. Hareket özelliği ve morfolojik karakterler izlenmiştir. Konsantre meyve özütünde, MMS + Konsantre meyve özütünde ve yalnızca MMS'de gelişen sinekler, uzun gelişme süresi, daha düşük yaşama gücü sergilemiş ve kanat gelişimi de olumsuz etkilenmiştir. Olumlu biyolojik etkiler \%2 ile 25 arası A. melanocarpa özütlü substratlarda gelişen sineklerde gözlenmiştir. Sadece MMS + \%25 meyve özütü karışımı, diğer MMS yan uygulamaları ile karşılaşıııılığında hareket bileşenleri ve kanat gelişiminin her ikisinde de tercih edilebilir etkiler göstermiş, bu karışımın MMS tarafından verilen hasara karşı hücreyi koruduğuna işaret etmiştir.
\end{abstract}

Anahtar sözcükler: gelişme süresi, yumurtadan çıkış dinamiği, metil metansülfonat, yaşama gücü, kanat şekli, kanat boyutu

\footnotetext{
${ }^{1}$ This work was funded by the Serbian Ministry of Education, Science and Technological Development (Grant 173038).

${ }^{2}$ University of Belgrade, Institute for Biological Research, Despot Stefan Blvd. 142, 11000, Belgrade, Serbia

${ }^{3}$ Shire, Uskočka 8, 11000, Belgrade, Serbia

${ }^{4}$ University of Belgrade, Faculty of Biology, Studentski trg 16, 11000, Belgrade, Serbia

${ }^{5}$ Nanyang Technological University, 50 Nanyang Avenue, 639798, Singapore

* Corresponding author (Sorumlu yazar) e-mail: tanjat@ibiss.bg.ac.rs

Received (Alınış): 09.11.2018 Accepted (Kabul ediliş): 19.01.2019 
"In different shades of purple": effects of different concentrations of commercial black chokeberry fruit extract [Aronia melanocarpa (Michx) Elliot] on fitness components and wing morphology of the fruit fly, Drosophila melanogaster Meigen, 1830

\section{Introduction}

The modern way of life and development of new technologies have increased the presence of physical and chemical agents in the environment that can cause changes in genetic material and cell damage. Mutations often cause different harmful effects, and their detection and prevention are imperatives of modern fundamental and applied genetic research. In this regard, the detection of substances which may have an adverse or protective effect is one of the most topical challenges of modern science. Many agents of biological and chemical origin exhibit great potential for primary prevention of diseases associated with an increased frequency of mutations (Gasiorowski et al., 1997; Zafra-Stone et al., 2007). Therefore, identification and purposeful use of natural antimutagens which adversely affect spontaneous and induced mutagenesis are of special interest.

It is widely accepted that some of the protective mechanisms in cells are associated with the activity of bioactive components of fruits and vegetables. Bioactive compounds may reduce oxidative stress, and hence have a beneficial effect by reducing the risk of many human diseases (Chrubasik et al., 2010). Darker fruits (e.g., blue and red berries) are known for their high antioxidant content. They are rich in polyphenols with reported beneficial effects on human health (Bermudez-Soto et al., 2007). Most of these polyphenols, which are responsible for the purple, blue, violet and black color of these fruits, are flavonoids from the anthocyanin subclass (Valcheva-Kuzmanova et al., 2004). In comparison with blueberries, cranberries and currants, it has been shown that black chokeberry [Aronia melanocarpa (Michx) Elliott] has a significantly higher content of anthocyanins and phenolic compounds (Jakobek et al., 2007; Kokotkiewicz et al., 2010). The biological effects of black chokeberry are mostly due to its high antioxidative activity, which is expected to diminish the formation of reactive oxygen species and oxidative DNA-damaging agents. Many important characteristics of black chokeberry, including its detailed chemical composition, antioxidant features, flavor and nutritional value, and high resistance to pollution and pests, have been thoroughly discussed (Sidhu \& Zafar, 2012). Aronia melanocarpa contains high concentrations of not only antioxidants (anthocyanins, biophenols, catechins, flavonoids and tannins), but also vitamins (A, B2, B6, B9, C and E) and very rare bioflavonoids (vitamin $\mathrm{P}$ ). Due to the wide range of multifunctional biological effects, interest in studying its biological activity has grown rapidly over the past decades.

Aronia melanocarpa is used in traditional medicine (Slimestad et al., 2005) and also as a food colorant (Briddle \& Timberlake, 1997), a food resource, and an ornamental plant (Kokotkiewicz et al., 2010). Many health-promoting activities of black chokeberry extracts were observed in both in vitro and in vivo studies (Kokotkiewicz et al., 2010). Recent papers suggest that $A$. melanocarpa and its products may be effective in prevention and treatment of the toxic action of some xenobiotics in humans (Borowska \& Brzóska, 2016; Case et al., 2016).

Given the limited knowledge on the effects of anthocyanins and phenolic compounds in in vivo systems, we considered study of the effects of $A$. melanocarpa extract to be worthwhile, especially during embryonic development. Furthermore, its protective effect when applied in synergy with toxic/mutagenic/carcinogenic substances is insufficiently known. It has been cautioned that more rigorous studies need to be carried out "before putative therapeutic uses can be confidently recommended for chokeberry products" (Chrubasik et al., 2010).

To our knowledge, different in vivo studies of the biological effects of black chokeberry were previously conducted on mammals (Valcheva-Kuzmanova et al., 2005; Valcheva-Kuzmanova \& Zhelyazkova-Savova, 2009; Kim et al., 2013; Sharif et al., 2013). Recently, Jo \& Imm (2017) reported about effects of black chokeberry extract on lifespan and age-related oxidative stress in Drosophila melanogaster Meigen, 1830. The present work represents one of the few experimental researches in which fruit fly was used as a model system to study the biological effects of $A$. melanocarpa. 
Drosophila melanogaster is a suitable test organism for examining the protective or genotoxic potential of different compounds. Metabolic activation of the enzymes in fruit flies is similar to that in the mammalian liver (Reiter et al., 2001; Lloyd \& Taylor, 2010), allowing at least partial extrapolation of the results obtained. The developmental time, dynamics of embryonic and post-embryonic development and viability represent fitness components important for understanding the possible effects of various environmental factors and chemical substances. The developmental capacity coordinates the expression of morphological, physiological and behavioral traits. Organisms have different investments in development of these features, depending on the environmental conditions. The Drosophila wing represents one of the appropriate models to perceive developmental changes reflected on the morphological level in the presence of different nutritional and chemical compounds. The availability and allocation of resources over larval time in adults can be perceived through analysis of the wings, i.e., wing morphology depends on environmental conditions during larval development (McGuigan, 2009). In this connection, we assumed that changes in fitness components and wing size and shape in fruit flies may indicate effects of both natural fruit extracts and mutagenic chemicals. Accordingly, co-treatments with methyl methanesulfonate (MMS) were applied simultaneously with pure black chokeberry treatments. Methyl methanesulfonate is a strong mutagen classified as a carcinogen, teratogen, and an agent which may cause developmental toxicity (Anonymous, 1987). It is also an apoptosis inducer, as well as an alkylating agent. In $D$. melanogaster, somatic and sex-linked recessive lethal mutations were induced after exposure of larvae or adults to MMS in their food (Mitchell et al., 1981).

\section{Material and Methods}

This study was conducted in 2016 at the Department of Genetics of Populations and Ecogenotoxicology, Institute for Biological Research, University of Belgrade.

\section{Aronia melanocarpa extract}

A commercial fruit extract of $A$. melanocarpa made by the Armedina Company, Belgrade, Surčin, Boljevci, Serbia, from fruits that originated from the Siberian region (Russian Federation) was used in the work. The extract was prepared without preservatives, alcohols, gluten or heat treatment. The $A$. melanocarpa extract was free of proteins and fats and contained $13.6 \%$ carbohydrates and a minimum of $0.6 \%$ vitamin $P$. The fruit extract was added to a standard cornmeal substrate instead of water in an amount needed to obtain the required concentration. The undiluted fruit extract was taken as a $100 \%$ solution.

\section{Drosophila melanogaster strain}

Wild type D. melanogaster stock, Canton S, obtained from the Bloomington Drosophila Stock Center, Indiana University, Bloomington, IN, USA, was used in the experiment. This strain was maintained under the optimal laboratory conditions for $D$. melanogaster $\left(25^{\circ} \mathrm{C}, 60 \% \mathrm{RH}, 300\right.$ lux 12:12 h L:D photoperiod).

\section{Chemicals}

Methyl methanesulfonate (MMS, CAS no. 66-27-3, Sigma-Aldrich, St Louis, MI, USA) at half of the half lethal dose $\left(L D_{50}\right), 1.5 \mathrm{mM}$ of MMS, was used in the experimental procedure.

\section{Experimental procedure}

Standard cornmeal substrate (ST) for Drosophila was used for strain maintenance and egg production. The substrate was composed of $9 \%$ sugar, $10 \%$ cornmeal, $2 \%$ agar and $2 \%$ yeast. As a moldinhibiting complement, nipagin dissolved in $96 \%$ alcohol was also added to the substrate.

Eggs (60 per vial) were randomly collected from 30 females, 3-8 d old, $8 \mathrm{~h}$ after they had been laid in Petri dishes. Egg-to-adult development was completed under optimal laboratory conditions, in $60 \mathrm{ml}$ vials. 
"In different shades of purple": effects of different concentrations of commercial black chokeberry fruit extract [Aronia melanocarpa (Michx) Elliot] on fitness components and wing morphology of the fruit fly, Drosophila melanogaster Meigen, 1830

Three experimental groups were formed (Figure 1). The first experimental group included negative (ST) and positive (1.5 mM concentration of methyl methanesulfonate, MMS, in standard medium) control subgroups. The second experimental (treatment) group consisted of the following three subgroups: flies fed on undiluted fresh fruit extract, flies fed on $2 \%$ fruit extract and flies fed on $25 \%$ fruit extract. Experimental subgroups consisting of flies developed on undiluted fresh fruit extract, $2 \%$ fruit extract and $25 \%$ fruit extract, each supplied with $1.5 \mathrm{mM} \mathrm{MMS}$, constituted the third experimental (co-treatment) group. Each control, treatment and co-treatment subgroup was replicated four times (Figure 1A).

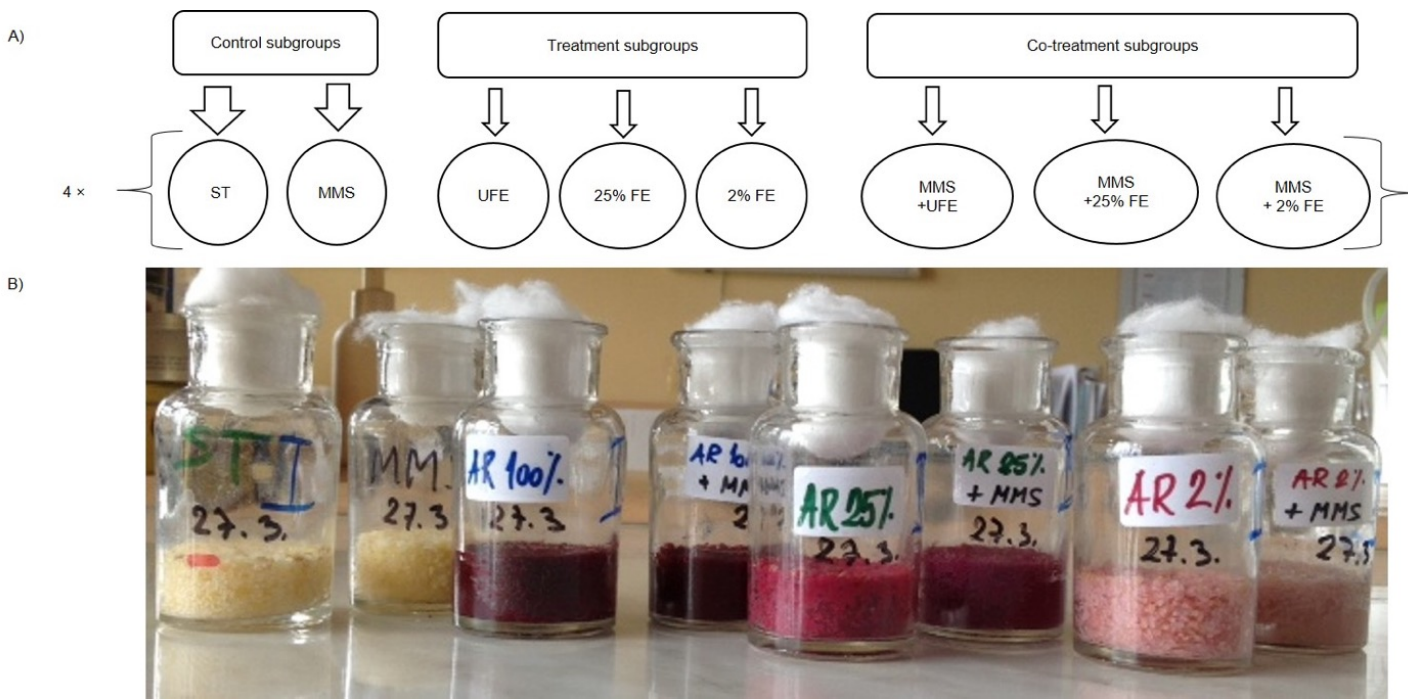

Figure 1. A) Scheme of the experimental design (Abbreviations: ST - standard cornmeal substrate - negative control subgroup; MMS - methyl methanesulfonate - positive control subgroup; UFE - undiluted fruit extract; $25 \% \mathrm{FE}$ - $25 \%$ fruit extract; $2 \% \mathrm{FE}$ - $2 \%$ fruit extract; MMS + UFE - MMS + undiluted fruit extract; MMS+25\% FE - MMS + 25\% fruit extract; MMS + 2\% FE - MMS + $2 \%$ fruit extract); B) Bottles with Drosophila melanogaster flies developed in the aforementioned food regimes.

\section{Fitness components}

In all experimental groups (control, treatment and co-treatments subgroups), flies were scored for developmental time $\left(D_{t}\right)$, hatching dynamics $\left(\Delta n_{t}\right)$ and viability $\left(V_{i}\right)$. Developmental time was measured in days, once all the adults have emerged, using the formula: $D_{t}=\left(\sum n_{d} \times d\right) / \sum n_{d}$, where $n_{d}$ is the number of flies emerging $d$ days after the eggs were laid. Dynamics of hatching was scored as the number of eclosed individuals at the same time of each day. Viability was calculated as the ratio of emerged adults to the number of laid eggs, according to the formula $V_{i}=n / N$, where $N$ is the total number of eggs, while $n$ is the number of adults emerging from the total number of eggs.

\section{Statistical analysis}

The Kolmogorov-Smirnov test was used to test the normality of the data for both developmental time and viability. The values of developmental time and viability were analyzed by one-way ANOVA. The Dunnett's post-hoc procedure was used to test the statistical significance of treatments and co-treatments in comparison with the negative control group.

\section{Analysis of wing size and shape}

Right wings of both sexes were used in an analysis of wing size and shape in the three experimental groups. All wings were individually photographed. Digital images were obtained on a Leica DM RB photomicroscope (Leica, Wetzlar, Germany) connected with a DFC320 CCD camera (Leica). A measurement scale of $0.5 \mathrm{~mm}$ was added to each wing photo in Adobe Photoshop CS5.1 (Adobe Inc, San 
Jose, California, USA). Measurement units were $0.1 \mathrm{~mm}$. Wings were marked with 11 reference marks using tpsDig2w32, a computer program for digitizing reference marks and outlines for geometric morphometric analyses (see: life.bio.sunysb.edu/morph/soft-dataacq.html) (Figure 2).

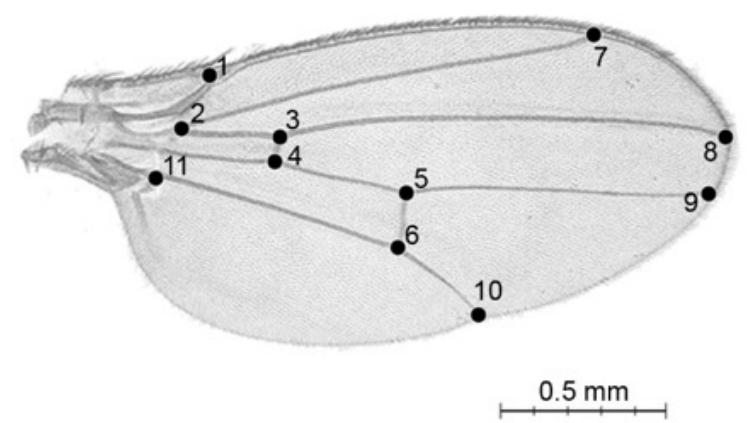

Figure 2. Drosophila melanogaster wing with 11 reference marks and measurement scale.

Wing size and shape were analyzed using the geometric morphometry approach in MorphoJ software (www.flywings.org.uk/MorphoJ_page.htm). Principal component analysis (PCA) was used to determine the total variability of wing size and shape in the whole sample, based on Procrustes coordinates. Regression of wing shape on centroid size was performed in order to determine whether there is a dependence between size and shape. Differences of wing centroid size as a function of treatments and cotreatments in comparison with the negative control group, as well as between the sexes, were tested using one-way ANOVA. Moreover, MANOVA was performed in order to test the variability of wing shape as a function of treatments and co-treatments in comparison with the negative control group, as well as between the sexes.

STATISTICA ${ }^{\circledR}$ version 5.0 (StatSoft, Inc., Tulsa, OK USA; www.statsoft.com) software was used for all statistical calculations.

\section{Results}

The Kolmogorov-Smirnov test confirmed that normality of variances existed in all cases, so it was not necessary to perform data transformation (Zar, 1999).

\section{Developmental time}

Mean developmental time in each experimental group is given in Table 1. The shortest developmental time (13.51 d) was observed in the negative control group (ST) and the longest (18.88 d) in the co-treatment that involved MMS with undiluted fruit extract.

One-way ANOVA indicated that different concentrations of $A$. melanocarpa in treatments and cotreatments significantly affected developmental time $(F=72.2 ; p<0.001)$. Dunnett's post-hoc test showed significantly longer developmental time in all experimental groups in comparison with the negative control group ( $p<0.001$ ), except in treatments with 2 and $25 \%$ fruit extract where that flies had significantly shorter development in comparison with the other experimental groups (LSD post-hoc test, $p<0.001$ ). 
"In different shades of purple": effects of different concentrations of commercial black chokeberry fruit extract [Aronia melanocarpa (Michx) Elliot] on fitness components and wing morphology of the fruit fly, Drosophila melanogaster Meigen, 1830

Table 1. Developmental time (d, mean $\pm \mathrm{SE}$ ) of Drosophila melanogaster in control, treatment and co-treatment subgroups

\begin{tabular}{llrl}
\hline Groups & Subgroups & \multicolumn{2}{c}{ Developmental time } \\
\hline \multirow{2}{*}{ Control } & negative control (ST) & $13.51 \pm 0.07$ \\
& positive control (MMS) & $17.80 \pm 0.09^{\mathrm{a}}$ \\
\hline \multirow{3}{*}{ Treatment } & 2\% fruit extract & $13.78 \pm 0.06^{\mathrm{a}, \mathrm{b}}$ \\
& $25 \%$ fruit extract & $14.32 \pm 0.04^{\mathrm{a}, \mathrm{b}}$ \\
& undiluted fruit extract & $18.87 \pm 0.14^{\mathrm{a}}$ \\
\hline \multirow{3}{*}{ Co-treatment } & $17.50 \pm 0.09^{\mathrm{a}}$ \\
& MMS + 2\% fruit extract & $15.06 \pm 0.05^{\mathrm{a}}$ \\
& MMS + 25\% fruit extract & $18.88 \pm 0.14^{\mathrm{a}}$ \\
\hline
\end{tabular}

${ }^{a} p<0.001$, significantly longer developmental time in all experimental groups in comparison with the negative control group;

${ }^{b} \mathrm{p}<0.001$, significantly shorter development in comparison with the other experimental groups.

\section{Dynamics of hatching adults}

For developmental time and dynamics of hatching, two groups were evident. Treatments with 2 and $25 \%$ A. melanocarpa fruit extract and MMS $+25 \%$ fruit extract co-treatment were in the first group, together with the negative control group. The second group consisted of the remaining co-treatments with MMS, treatment with the undiluted fruit extract and the positive control group.

Hatching of adults of the negative control group and from the substrate with $2 \%$ fruit extract started on day 12 , while it started on days 13 and 14 from substrates with $25 \%$ fruit extract and MMS $+25 \%$ fruit extract, respectively (Figure 3). The peak of eclosion in the experimental groups with $2 \%$ fruit extract, $25 \%$ fruit extract and MMS $+25 \%$ fruit extract was observed 1 and $2 \mathrm{~d}$ later $(51.7 \%$ hatched individuals from the substrate with $2 \%$ fruit extract on day $14,64.0 \%$ hatched individuals from the substrate with $25 \%$ fruit extract on day 14 , and $72.7 \%$ hatched individuals from the substrate with MMS $+25 \%$ extract on day 15 ) in comparison with the negative control group ( $46.5 \%$ hatched individuals on day 13). Adults from these groups finished eclosion between day 16 (those that developed on substrates with $2 \%$ and $25 \%$ fruit extract) and day 17 (in the negative control group and in flies that developed on the substrate supplied with MMS $+25 \%$ fruit extract).

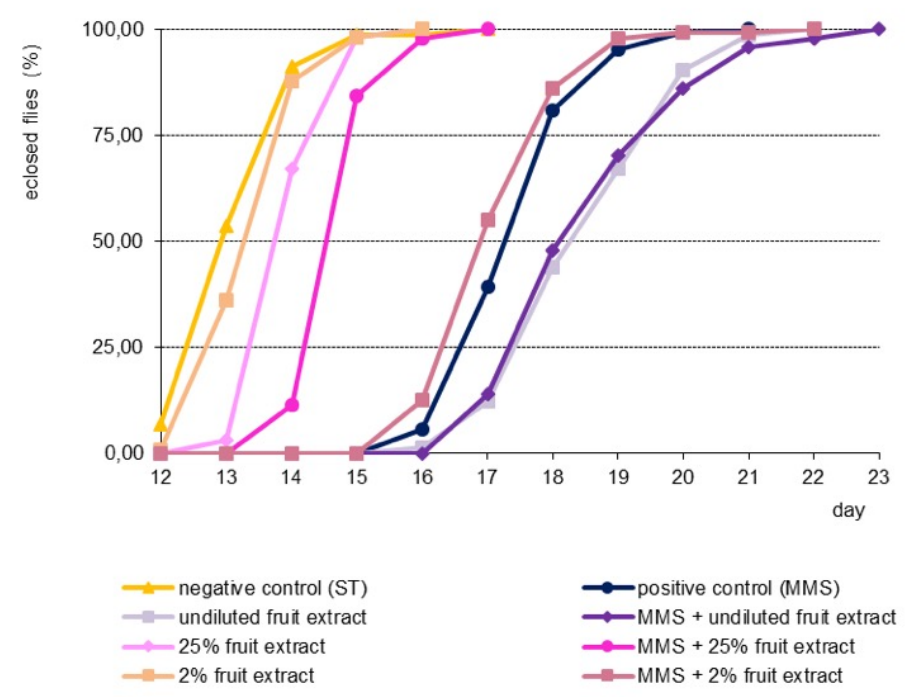

Figure 3. Dynamics of hatching of Drosophila melanogaster adults in all experimental subgroups. 
Eclosion of adults from undiluted $A$. melanocarpa fruit extract, MMS, and co-treatments with MMS started from day 16 (MMS + 2\% fruit extract) and day 17 (MMS + undiluted fruit extract). The highest number of eclosed adults (42.7\%) was detected on day 17 in the MMS $+2 \%$ extract co-treatment and on day 18 on substrates with undiluted $A$. melanocarpa fruit extract $(31.7 \%)$, MMS $(41.6 \%)$, and their cotreatment (34.0\%). Hatching in these experimental groups was finished on day 21 (from the substrate with MMS), on day 22 (from the substrate with undiluted fruit extract and that with MMS $+2 \%$ fruit extract), and on day 23 (from the substrate with MMS + undiluted fruit extract).

\section{Viability}

The ratio of eclosed adults and eggs laid was used to indicate viability, as it further contributes to the overall picture of complete development. Figure 4 shows the number of eclosed $D$. melanogaster adults in the control conditions and during exposure to the treatments and co-treatments. The lowest viability was found in treatment and co-treatment with the undiluted fruit extract, while individuals that developed on the substrate with $25 \%$ fruit extract showed the highest viability. From the highest to the lowest, viability in the experimental subgroups were as follows: $25 \%$ fruit extract $>$ standard substrate, negative control subgroup $>2 \%$ fruit extract $>M M S+25 \%$ fruit extract $>M M S+2 \%$ fruit extract $>M M S$, positive control subgroup $>$ MMS + undiluted fruit extract $>$ undiluted fruit extract. One-way ANOVA showed significant differences in viability among treatments and co-treatments $(F=8.83 ; p<0.001)$. Dunnett's post-hoc test indicated that viability was significantly lower in the case of treatment and co-treatment with undiluted fruit extract in comparison with the negative control group $(p<0.05)$.

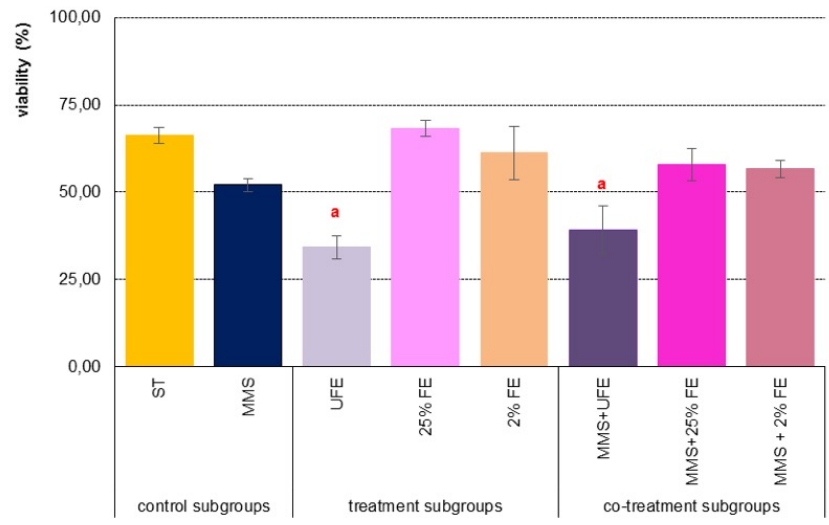

Figure 4. Mean viability \pm SE (\%) of Drosophila melanogaster in control treatment and co-treatment subgroups (Abbreviations: ST standard cornmeal substrate - negative control subgroup; MMS - methyl methanesulfonate - positive control subgroup; UFE - undiluted fruit extract; $25 \% \mathrm{FE}$ - $25 \%$ fruit extract; $2 \% \mathrm{FE}$ - $2 \%$ fruit extract; MMS + UFE - MMS + undiluted fruit extract; MMS $+25 \%$ FE - MMS + $25 \%$ fruit extract; MMS + $2 \%$ FE - MMS + $2 \%$ fruit extract; a - significantly lower viability in comparison with the negative control subgroup (Dunnett's post-hoc test $p<0.05$ ).

\section{Analysis of wing size and shape}

Table 2 shows mean values and the standard error of centroid size (CS). PCA showed separation of all of the aforementioned groups in regard to wing shape and size, as well as sexual dimorphism in those traits. The first principal component (PC1) described $23.1 \%$ of the variability in the whole sample, and PC2 and PC3, 12.7 and $12.4 \%$, respectively. Most of the variability of wing size and shape in females from all experimental groups is described by the first four principal components, which constituted $55.1 \%$ of the total variability $(\mathrm{PC} 1=19.1 \%, \mathrm{PC} 2=13.4 \%, \mathrm{PC} 3=12.6 \%$, and PC4 $=10.1 \%)$. For males, most of the variability in wing size and shape was defined by the first three principal components, which comprised $46.1 \%$ of total variability $(\mathrm{PC} 1=21.6 \%, \mathrm{PC} 2=13.0 \%$, and $\mathrm{PC} 3=11.6 \%)$. The regression curve showed that the allometry is $10.4 \%$ of the size of the whole sample $(p<0.0001)$. 
"In different shades of purple": effects of different concentrations of commercial black chokeberry fruit extract [Aronia melanocarpa (Michx) Elliot] on fitness components and wing morphology of the fruit fly, Drosophila melanogaster Meigen, 1830

Table 2. Wing centroid size (mean $\pm \mathrm{SE}$, in $\mathrm{mm}$ ) in Drosophila melanogaster females and males from control, treatment, and cotreatment subgroups

\begin{tabular}{llllll}
\hline Groups & Subgroups & \multicolumn{2}{c}{ Females } & \multicolumn{2}{c}{ Males } \\
\hline \multirow{2}{*}{ Control } & negative control (ST) & $2.30 \pm 0.08$ & 2.07 & \pm 0.08 \\
& positive control (MMS) & 2.30 & \pm 0.11 & 2.06 & \pm 0.08 \\
\hline \multirow{3}{*}{ Treatment } & 2\% fruit extract & $2.39 \pm 0.11^{\mathrm{a}}$ & $2.12 \pm 0.08^{\mathrm{a}}$ \\
& 25\% fruit extract & $2.32 \pm 0.11$ & $2.09 \pm 0.10$ \\
& undiluted fruit extract & $2.17 \pm 0.11^{\mathrm{b}}$ & $2.00 \pm 0.10^{\mathrm{b}}$ \\
\hline \multirow{3}{*}{ Co-treatment } & MMS + 2\% fruit extract & $2.34 \pm 0.12$ & $2.09 \pm 0.09$ \\
& MMS + 25\% fruit extract & $2.33 \pm 0.09$ & $2.05 \pm 0.08$ \\
& MMS + undiluted fruit extract & $2.16 \pm 0.10^{\mathrm{b}}$ & $1.97 \pm 0.13^{\mathrm{b}}$ \\
\hline
\end{tabular}

a significantly larger wings in comparison with the negative control subgroup;

${ }^{\mathrm{b}}$ significantly smaller wings than flies from the negative control subgroup.

ANOVA (Table 3) and MANOVA (Table 4) confirmed sexual dimorphism for both centroid size and wing shape. Females possessed significantly larger wings than males in all experimental groups.

Table 3. Sexual dimorphism in centroid size, tested by ANOVA, in all experimental subgroups

\begin{tabular}{llcccccc}
\hline Groups & Subgroups & df & Error df & MS & Error MS & \multicolumn{1}{c}{ F } & \\
\hline \multirow{2}{*}{ Control } & negative control (ST) & 1 & 90 & 11.876 & 0.0069 & 172.10 & $* * *$ \\
& positive control (MMS) & 1 & 92 & 12.877 & 0.0098 & 131.66 & $* * *$ \\
\hline \multirow{3}{*}{ Treatment } & 2\% fruit extract & 1 & 99 & 18.426 & 0.0089 & 207.60 & $* * *$ \\
& 25\% fruit extract & 1 & 124 & 17.679 & 0.0112 & 157.94 & $* * *$ \\
& Undiluted fruit extract & 1 & 52 & 0.3565 & 0.0110 & 32.47 & $* * *$ \\
\hline \multirow{3}{*}{ Co-treatment } & MMS + 2\% fruit extract & 1 & 79 & 12.595 & 0.0122 & 103.40 & $* * *$ \\
& MMS + 25\% fruit extract & 1 & 73 & 14.987 & 0.0081 & 184.16 & $* * *$ \\
& MMS + Undiluted fruit extract & 1 & 57 & 0.5694 & 0.0131 & 43.32 & $* * *$ \\
\hline
\end{tabular}

${ }^{* * *} p<0.001$

Table 4. Sexual dimorphism in wing shape, tested by MANOVA, in all experimental subgroups

\begin{tabular}{|c|c|c|c|c|c|c|}
\hline Groups & Subgroups & df & Error df & Wilk's & $\mathrm{F}$ & \\
\hline \multirow{2}{*}{ Control } & negative control (ST) & 18 & 73 & 0.2214 & 22.41 & $* * *$ \\
\hline & positive control (MMS) & 18 & 75 & 0.2332 & 13.70 & $* * *$ \\
\hline \multirow{3}{*}{ Treatment } & $2 \%$ fruit extract & 18 & 82 & 0.1542 & 24.99 & *** \\
\hline & $25 \%$ fruit extract & 18 & 107 & 0.2214 & 20.91 & *** \\
\hline & Undiluted fruit extract & 18 & 35 & 0.2589 & 5.56 & *** \\
\hline \multirow{3}{*}{ Co-treatment } & MMS $+2 \%$ fruit extract & 18 & 62 & 0.2158 & 12.52 & *** \\
\hline & MMS $+25 \%$ fruit extract & 18 & 56 & 0.2407 & 9.82 & $* * *$ \\
\hline & MMS + Undiluted fruit extract & 18 & 40 & 0.1175 & 16.69 & $* * *$ \\
\hline
\end{tabular}

*** $p<0.001$

The ANOVA showed significant differences in centroid size between the control groups and some of the treated groups (Table 5). Females and males treated with $2 \%$ extract had significantly larger wings compared with females and males from the negative control group. Flies that developed on undiluted fruit extract and MMS + undiluted fruit extract possessed smaller wings than flies from the negative control subgroup (Table 5). 
Table 5. One-way ANOVA of wing centroid size in females and males subjected to treatments and co-treatments compared with the negative control subgroup

\begin{tabular}{|c|c|c|c|c|c|c|c|c|}
\hline Groups & Subgroups & Sex & df & Error df & MS & Error MS & $\mathrm{F}$ & \\
\hline \multirow{2}{*}{ Control } & \multirow{2}{*}{ MMS - positive control } & q & 1 & 105 & 0.0000 & 0.0095 & 0.00 & \\
\hline & & 0 & 1 & 77 & 0.0036 & 0.0068 & 0.53 & \\
\hline \multirow{6}{*}{ Treatment } & \multirow{2}{*}{$2 \%$ fruit extract } & q & 1 & 95 & 0.1839 & 0.0093 & 19.84 & *** \\
\hline & & $\pi$ & 1 & 94 & 0.0467 & 0.0066 & 7.10 & $* *$ \\
\hline & \multirow{2}{*}{$25 \%$ fruit extract } & q & 1 & 111 & 0.0127 & 0.0097 & 1.31 & \\
\hline & & 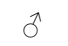 & 1 & 103 & 0.0036 & 0.0091 & 0.40 & \\
\hline & \multirow{2}{*}{ Undiluted fruit extract } & q & 1 & 70 & 0.2997 & 0.0085 & 35.24 & $* * *$ \\
\hline & & 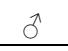 & 1 & 72 & 0.0949 & 0.0083 & 11.44 & ** \\
\hline \multirow{6}{*}{ Co-treatment } & \multirow{2}{*}{ MMS $+2 \%$ fruit extract } & q & 1 & 89 & 0.0326 & 0.0108 & 3.01 & \\
\hline & & $0^{\lambda}$ & 1 & 80 & 0.0049 & 0.0077 & 0.63 & \\
\hline & \multirow{2}{*}{ MMS $+25 \%$ fruit extract } & q & 1 & 89 & 0.0217 & 0.0078 & 2.77 & \\
\hline & & 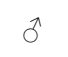 & 1 & 74 & 0.0139 & 0.0070 & 1.99 & \\
\hline & \multirow{2}{*}{ MMS + Undiluted fruit extract } & q & 1 & 72 & 0.3223 & 0.0078 & 41.55 & *** \\
\hline & & 3 & 1 & 75 & 0.2226 & 0.0108 & 20.57 & $* * *$ \\
\hline
\end{tabular}

${ }^{* *} \mathrm{p}<0.01 ;{ }^{* * *} \mathrm{p}<0.001 ;$; - female, $\hat{o}-$ male

The MANOVA showed significant differences of wing shape without allometry effects between the control group and treatments with $2 \%$ fruit extract and undiluted fruit extract, as well as between the control group and co-treatment with MMS + undiluted fruit extract in both sexes (Table 6). It was also noticed that only females in treatment with MMS and in co-treatment with MMS $+2 \%$ fruit extract had a significantly different wing shape without allometry effects in comparison with the negative control group. Differences of wing shape for females and males are shown in Figure 5.

Table 6. One-way MANOVA of wing shape without allometry effects in females and males subjected to treatments and co-treatments compared with the negative control subgroup

\begin{tabular}{|c|c|c|c|c|c|c|c|}
\hline Groups & Subgroups & & $\mathrm{df}$ & Error df & Wilk's & $\mathrm{F}$ & \\
\hline \multirow{2}{*}{ Control } & \multirow{2}{*}{ positive control (MMS) } & q & 18 & 77 & 0.617 & 2.66 & ** \\
\hline & & 0 & 18 & 75 & 0.759 & 1.33 & \\
\hline \multirow{6}{*}{ Treatment } & \multirow{2}{*}{$2 \%$ fruit extract } & 우 & 18 & 92 & 0.533 & 4.49 & *** \\
\hline & & 0 & 18 & 85 & 0.625 & 2.83 & $* * *$ \\
\hline & \multirow{2}{*}{$25 \%$ fruit extract } & 우 & 18 & 50 & 0.841 & 0.53 & \\
\hline & & 0 & 18 & 54 & 0.852 & 0.52 & \\
\hline & \multirow{2}{*}{ Undiluted fruit extract } & 우 & 18 & 71 & 0.475 & 4.35 & *** \\
\hline & & 0 & 18 & 61 & 0.519 & 3.14 & $* * *$ \\
\hline \multirow{6}{*}{ Co-treatment } & \multirow{2}{*}{ MMS $+2 \%$ fruit extract } & 오 & 18 & 70 & 0.627 & 2.31 & ** \\
\hline & & 0 & 18 & 56 & 0.658 & 1.62 & \\
\hline & \multirow{2}{*}{ MMS $+25 \%$ fruit extract } & 우 & 18 & 54 & 0.869 & 0.45 & \\
\hline & & 0 & 18 & 52 & 0.823 & 0.62 & \\
\hline & \multirow{2}{*}{ MMS + Undiluted fruit extract } & 우 & 18 & 87 & 0.661 & 2.47 & ** \\
\hline & & 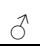 & 18 & 59 & 0.552 & 2.66 & $* *$ \\
\hline
\end{tabular}

${ }^{* *} p<0.01 ;{ }^{* * *} p<0.001 ;$; - female, ô $^{-}$male 
"In different shades of purple": effects of different concentrations of commercial black chokeberry fruit extract [Aronia melanocarpa (Michx) Elliot] on fitness components and wing morphology of the fruit fly, Drosophila melanogaster Meigen, 1830
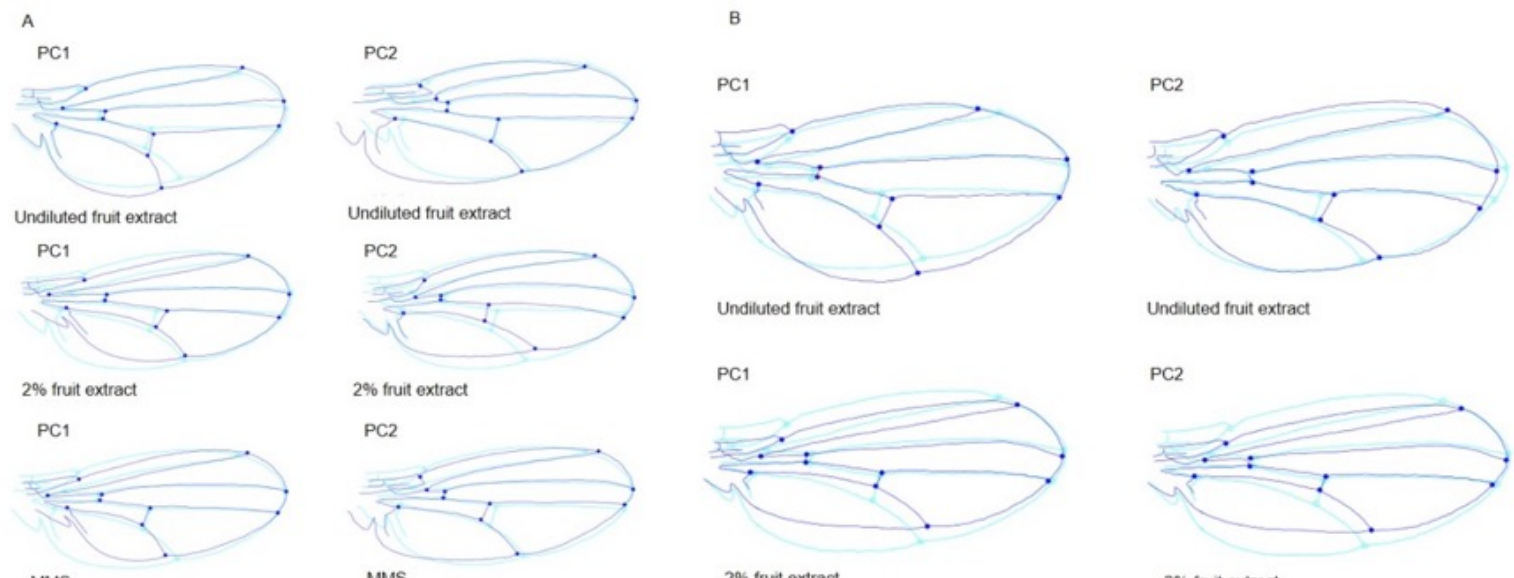

Undiluted fruit extract
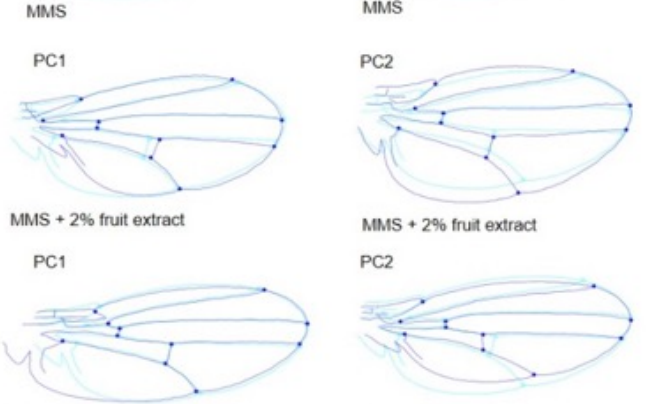

29 fruit extract

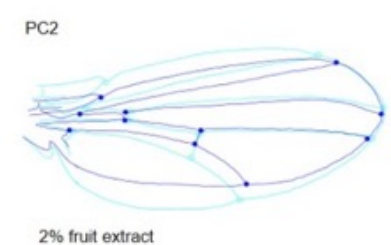

PC1

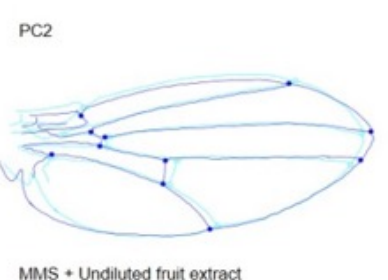

MMS + Undiluted fruit extract

MMS + Undiluted fruit extract

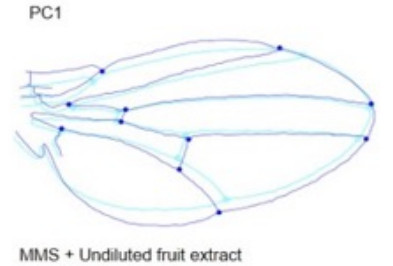

MMS + Undiluted fruit extract

Figure 5. Differences in wing shape in females $(A)$ and in males (B) from the positive control subgroup, treatment subgroups and cotreatment subgroups in relation to the negative control subgroup.

\section{Discussion}

It is already known that bioactive substances, including components from black chokeberry, may reduce the induction of mutagenesis and prevent many degenerative diseases, cancer among them. However, some of those components can be toxic or even increase mortality (Bjelakovic et al., 2008). Given that a large number of bioactive plant products are used as supplements in human and animal diets, it is crucial to determine both their protective and their harmful concentrations (doses). In the study presented here, different concentrations of $A$. melanocarpa fruit extract were added to the food of $D$. melanogaster larvae, and its biological effects were monitored during development (fitness traits) and in adults of the first generation of offspring (morphological traits).

During insect development, larval pattern building and metamorphosis are considered as two different developmental processes that contribute to the formation of adults (Nascimento et al., 2002). It is known that the developmental time of each preimaginal stage, including the embryonic period (phase), regulates the time needed for body development, fitting the developmental time into the environmental conditions. Accordingly, the developmental time represents an adaptive trait and is thereby a crucial selective component in the existence of insects living in environments that are changeable in regard to the source and quality of the food. Whereas, viability, which reflects successfully completed development from eggs to adults, can be also considered as an important factor in assessing the effect of different environmental conditions.

The obtained data indicate that a significantly shorter development and higher viability were observed only in flies that developed on substrates containing 2 and $25 \%$ A. melanocarpa fruit extract in comparison to the other treatments and co-treatments. However, flies that developed on undiluted fruit extract, on MMS 
+ undiluted fruit extract, and on MMS alone exhibited a prolonged developmental time and had lower viability. Only a mixture of MMS $+25 \%$ extract showed positive effects on fitness components in comparison with other MMS co-treatments. This may indicate a possible chemopreventive potential of black chokeberry when used as a fruit extract diluted to quarter-strength. Previously published studies confirmed the wide range of positive biological effects of $A$. melanocarpa, including antioxidant, antibacterial, antiviral, antimutagenic, anticancerogenic, antidiabetic and antiinflammatory effects, as well as its cardioprotective, hepatoprotective and gastroprotective properties, under both in vivo and in vitro conditions (Gasiorowski et al., 1997; Simeonov et al., 2002; Surh, 2003; Matsumoto et al., 2004; Valcheva-Kuzmanova et al., 2004; Ohgami et al., 2005; Puupponen-Pimiä et al., 2005; Valcheva-Kuzmanova et al., 2007; Zafra-Stone et al., 2007; Nikolova et al., 2012).

Considering these results, black chokeberry fruit extract could be expected to have a protective effect against MMS, i.e., it can fix disturbances induced during development. However, the present study showed that the influence of black chokeberry fruit extract on fitness components was not beneficial in all cases and was even detrimental in higher concentrations.

Wing size and shape in Drosophila represent a convenient model for investigation, for both measurements and analysis, of the developmental control of phenotypic variation (Houle et al., 2010). The polygenic determination of wing shape, which is independent from that of wing size, is based on the action of genes generally involved in development and/or metabolic functions, especially those related to the regulation of different cellular processes, such as motility, adhesion, communication, and signal transduction (Carreira et al., 2011). The final size and shape of the Drosophila wing are the result of tight coordination of cell proliferation, apoptosis, cell allocation and mitotic orientation (de Celis, 2003; Palsson \& Gibson, 2004; Baena-López et al., 2005; Dworkin \& Gibson, 2006; Trotta et al., 2011). In that sense, the patterns of wing size and shape variation were useful in identifying possible morphological responses to different concentrations of $A$. melanocarpa extract, as well as to co-treatments with MMS.

In the present study, females had significantly larger wings than males in all experimental groups, as expected, since sexual dimorphism in body size is well known in D. melanogaster (Testa et al., 2013; Takahashi \& Blanckenhorn, 2015). However, females and males treated with undiluted fruit extract and with MMS + undiluted fruit extract possessed significantly smaller wings than females and males from the negative control subgroup. The used of $1.5 \mathrm{mM}$ MMS in the experimental procedure, as half of the half lethal dose (LD50), had no significant effect on wing centroid size comparing to negative control subgroup. Significant differences in wing centroid size obtained in treatment undiluted fruit extract and MMS + undiluted fruit extract can be explained as the effect of fruit extract. Flies feeding on these substrates exhibited a prolonged developmental time and had lower viability and therefore, possibly, had significantly smaller wing centroid size comparing to negative control subgroup. Also, the high amount of sugar in undiluted fruit extract can cause smaller wings.

Females and males treated with $2 \%$ fruit extract had significantly larger wings compared with females and males from the negative control subgroup, and these differences can be influenced by the sugar linked to the anthocyanidin. The biological activity of $A$. melanocarpa extracts have been reported to be influenced by the sugar units linked to the anthocyanidin (Bräunlich et al., 2013).

Flies in the co-treatment MMS $+2 \%$ fruit extract had slightly smaller wings and prolonged developmental time, but there were no differences compared to negative control group. The co-treatments effect was mostly reflected through the components of the fitness. This suggests the possibility that high concentrations of $A$. melanocarpa fruit extract have a negative impact on wing size. In the case of wing shape, significant differences were observed between some of the treatments and co-treatments in comparison with the negative control subgroup, also confirming their impact on wing development. Carreira et al. (2011) shows that more than $63 \%$ of induced mutations affected wing shape in one or both sexes, 
"In different shades of purple": effects of different concentrations of commercial black chokeberry fruit extract [Aronia melanocarpa (Michx) Elliot] on fitness components and wing morphology of the fruit fly, Drosophila melanogaster Meigen, 1830

although only $33 \%$ showed significant differences in both males and females. The reason for the absence of differences in wing shape between males from the positive subgroup comparing to negative control subgroup can be the results of sex-linked recessive changes that are expressed only in homozygous conditions. Hence, differences in wing shape between females from the MMS subgroup compared to the negative control subgroup were observed. Many genes contributing to the wing shape in a sexually dimorphic manner because of the complexity of its genetic architecture (Carreira et al., 2011). Different levels of carbohydrates and proteins in substrates on which Drosophila is feeding may change the duration and stability of development and, therefore, the size, shape and symmetry of certain adult traits (Shingleton, 2010; Trajković et al., 2013).

Aronia melanocarpa represents one of the richest plant sources of procyanidins and anthocyanins, which are potent antioxidants that destroy free radicals (Santrucek \& Krepdka, 1988) and as a result have a wide range of potential medical, therapeutic and nutritive effects (Lala et al., 2006). It was found that anthocyanins isolated from black chokeberry significantly inhibit the mutagenic activity of benzo (a) pyrene and 2-aminofluorene (Gasiorowski et al., 1997). In addition, in the presence of black chokeberry extract, the histopathological changes caused by $\mathrm{N}$-nitrosamines in the rat liver did not occur (Atanasova-Goranova et al., 1997). Beneficial effects of $A$. melanocarpa on behavior were also observed in animal models, such effects being expressed in increased locomotion, and reduction of anxiety-like and depression-like behavior (Tomić et al., 2016). However, the results of our research strongly indicate the need to define the range of concentrations which can provide a proper balance and be safely used for human disease prevention and therapeutic purposes. Otherwise, without accurate determination, either of both extremes, oxidative and antioxidative stress, might arise and could be deleterious (Poljsak et al., 2013). In conclusion, to judge from the results of analyzing both fitness and morphological traits in the present study, it would appear that $A$. melanocarpa extract in a concentration of $25 \%$, administered together with MMS, decreases the deleterious effects of MMS during development.

Further studies using different genotoxic tests are needed in order to analyze mechanisms governing the action of black chokeberry fruit extract and its components. The similarity of metabolic pathways in Drosophila and mammals (Reiter et al., 2001; Leopold \& Perrimon, 2007; Lloyd \& Taylor, 2010; OwusuAnsah \& Perrimon, 2014) would make the results of these tests widely applicable.

\section{Acknowledgments}

This work was funded by the Serbian Ministry of Education, Science and Technological Development (Grant 173038).

\section{References}

Anonymous, 1987. IARC Working Group on the Evaluation of Carcinogenic Risks to Humans: Overall Evaluations of Carcinogenicity. An updating of IARC Monographs Volumes 1 to 42 (Vol. 7): 442 pp.

Atanasova-Goranova, V. K., P. I. Dimova \& G. T. Pevicharova, 1997. Effect of food products on endogenous generation of $\mathrm{N}$-nitrosamines in rats. British Journal of Nutrition, 78: 335-345.

Baena-López, L. A., A. Baonza \& A. García-Bellido, 2005. The orientation of cell divisions determines the shape of Drosophila organs. Current Biology, 15: 1640-1644.

Bermudez-Soto, M. J., F. A. Tomas-Barberan \& M. T. Garcla-Conesa, 2007. Stability of polyphenols in chokeberry (Aronia melanocarpa) subjected to in vitro gastric and pancreatic digestion. Food Chemistry, 102: 865-874.

Bjelakovic, G., D. Nikolova, L. L. Gluud, R. G. Simonetti \& C. Gluud, 2008. Antioxidant supplements for prevention of mortality in healthy participants and patients with various diseases. Cochrane Database of Systematic Reviews, 16: CD007176.

Borowska, S. \& M. M. Brzóska, 2016. Chokeberries (Aronia melanocarpa) and their products as a possible means for the prevention and treatment of noncommunicable diseases and unfavorable health effects due to exposure to xenobiotics. Comprehensive Reviews in Food Science and Food Safety, 15: 982-1017. 
Bräunlich, M., R. Slimestad, H. Wangensteen, C. Brede, K. E. Malterud \& H. Barsett, 2013. Extracts, anthocyanins and procyanidins from Aronia melanocarpa as radical scavengers and enzyme inhibitors. Nutrients, 5: 663-678.

Briddle, P. \& C. F. Timberlake, 1997. Anthocyanins as natural food colour-selected aspects. Food Chemistry, 58: 103-109.

Carreira, V.P., I. M. Soto, J. Mensch \& J. J. Fanara, 2011. Genetic basis of wing morphogenesis in Drosophila: sexual dimorphism and non-allometric effects of shape variation. BMC Developmental Biology, 11 (32): 1-16.

Case, J., D. Agraz, I. M. Ahmad \& M. C. Zimmerman, 2016. Low-dose Aronia melanocarpa concentrate attenuates paraquat-induced neurotoxicity. Oxidative Medicine and Cellular Longevity, Volume 2016, ID 5296271: 1-11.

Chrubasik, C., G. Li \& S. Chrubasik, 2010. The clinical effectiveness of chokeberry: A systematic review. Phytotherapy Research, 24: 1107-1114.

de Celis, J. F., 2003. Pattern formation in the Drosophila wing: The development of the veins. Bioassays, 25: 443-451.

Dworkin, I. \& G. Gibson, 2006. Epidermal growth factor receptor and transforming growth factor- signaling contributes to variation for wing shape in Drosophila melanogaster. Genetics, 173: 1417-1431.

Gasiorowski, K., K. Szyba, B. Brokos, B. Kołaczyńska, M. Jankowiak-Włodarczyk \& J. Oszmiański, 1997. Antimutagenic activity of anthocyanins isolated from Aronia melanocarpa fruits. Cancer Letters, 119: 37-46.

Houle, D., D. R. Govindaraju \& S. Omholt, 2010. Phenomics: The next challenge. Nature Reviews Genetics, 11: $855-866$.

Jakobek, L., M. Seruga, M. Medvedovic-Kosanovic \& I. Novak, 2007. Antioxidant activity and polyphenols of aronia in comparison to other berry species. Agriculturae Conspectus Scientificus, 72: 301-306.

Jo, A.R. \& J. Y. Imm, 2017. Effects of aronia extract on lifespan and age-related oxidative stress in Drosophila melanogaster. Food Science and Biotechnology, 26 (5): 1399-1406.

Kim, B., C. S. Ku, T. X. Pham, Y. Park, D. A. Martin, L. Xie, R. Taheri, J. Lee \& B. W. Bolling, 2013. Aronia melanocarpa (chokeberry) polyphenol-rich extract improves antioxidant function and reduces total plasma cholesterol in apolipoprotein E knockout mice. Nutrition Research, 33: 406-413.

Kokotkiewicz, A., Z. Jaremicz \& M. Luczkiewicz, 2010. Aronia plants: a review of traditional use, biological activities, and perspectives for modern medicine. Journal of Medicinal Food, 13: 255-269.

Lala, G., M. Malik, C. Zhao, J. He, Y. Kwon, M. M. Giusti \& B. A. Magnuson, 2006. Anthocyanin-rich extracts inhibit multiple biomarkers of colon cancer in rats. Nutrition and Cancer, 54: 84-93.

Leopold, P. \& N. Perrimon, 2007. Drosophila and the genetics of the internal milieu. Nature, 450: 186-188.

Lloyd, T. E. \& J. P. Taylor, 2010. Flightless flies: Drosophila models of neuromuscular disease. Annals of the New York Academy of Sciences, 1184: e1-e20.

Matsumoto, M., H. Hara, H. Chiji \& T. Kasai, 2004. Gastroprotective effect of red pigments in black chokeberry fruit (Aronia melanocarpa Elliot) on acute gastric hemorrhagic lesions in rats. Journal of Agricultural and Food Chemistry, 52: 2226-2229.

McGuigan, K., 2009 Condition dependence varies with mating success in male Drosophila bunnanda. Journal of Evolutionary Biology, 22: 1813-1825.

Mitchell, I. D., P. J. Gilbert, A. J. Brice \& D. J. White, 1981. Somatic eye mutation in Drosophila melanogaster as a short-term test for mutagens and carcinogens. Carcinogenesis, 2: 783-786.

Nascimento, J. C., I. B. M. Cruz, L. A. Monjeló \& A. K. Oliveira, 2002. Genetic components affecting embryonic developmental time of Drosophila melanogaster. Genetics and Molecular Biology, 25: 157-160.

Nikolova, E., S. Valcheva-Kuzmanova, T. Markova, M. Krachanova \& P. Denev, 2012. Chemoprotective, antioxidant and immunomodulatory in vitro effects of Aronia melanocarpa total extract on laboratory-cultivated normal and malignant cells. Journal of BioScience and Biotechnology, SE: 35-43.

Ohgami, K., I. Ilieva, K. Shiratori, Y. Koyama, X.H. Jin, K. Yoshida, S. Kase, N. Kitaichi, Y. Suzuki, T. Tanaka \& S. Ohno, 2005. Antiinflammatory effects of Aronia extract on rat endotoxin-induced uveitis. Investigative Ophthalmology and Visual Science, 46: 275-281.

Owusu-Ansah, E. \& N. Perrimon, 2014. Modeling metabolic homeostasis and nutrient sensing in Drosophila: implications for aging and metabolic diseases. Disease Models and Mechanisms, 7: 343-350. 
"In different shades of purple": effects of different concentrations of commercial black chokeberry fruit extract [Aronia melanocarpa (Michx) Elliot] on fitness components and wing morphology of the fruit fly, Drosophila melanogaster Meigen, 1830

Palsson, A. \& G. Gibson, 2004. Association between nucleotide variation in Egfr and wing shape in Drosophila melanogaster. Genetics, 167: 1187-1198.

Poljsak, B., D. Šuput \& I. Milisav, 2013. Achieving the balance between ROS and antioxidants: When to use the synthetic antioxidants. Oxidative Medicine and Cellular Longevity, Volume 2013, ID 956792: 1-11.

Puupponen-Pimiä, R., L. Nohynek, H. L. Alakomi \& K. M. Oksman-Caldentey, 2005. Bioactive berry compounds-novel tools against human pathogens. Applied Microbiology and Biotechnology, 67: 8-18.

Reiter, L. T., L. Potocki, S. Chien, M. Gribskov \& E. A. Bier, 2001. A systematic analysis of human disease-associated gene sequences in Drosophila melanogaster. Genome Research, 11: 1114-1125.

Santrucek, M. \& J. Krepdka, 1988. Antioxidants - potential chemotherapeutic agents. Drugs of the Future, 13 (10): $974-996$.

Sharif, T., M. Stambouli, B. Burrus, F. Emhemmed, I. Dandache, C. Auger, N. Etienne-Selloumet, V. B. Schini-Kerth \& G. Fuhrmann, 2013. The polyphenolic-rich Aronia melanocarpa juice kills teratocarcinomal cancer stem-like cells, but not their differentiated counterparts. Journal of Functional Foods, 5: 1244-1252.

Shingleton, A. W., 2010. The regulation of organ size in Drosophila physiology, plasticity, patterning and physical force. Organogenesis, 6: 76-87.

Sidhu, J. S. \& T. A. Zafar, 2012. "Super Fruits: Pomegranate, Wolfberry, Aronia (Chokeberry), Acai, Noni and Amla, 653-679". In: Handbook of Fruits and Fruit Processing (Eds. N. K. Sinha, J. S. Sidhu, J. Barta, J. S. B. Wu \& M. Pilar Cano). 2nd Ed.: Wiley-Blackwell, A John Wiley \& Sons, Ltd., Publication, UK, 694 pp.

Simeonov, S. B., N. P. Botushanov, E. B. Karahanian, M. B. Pavlova, H. K. Husianitis \& D. M. Troev, 2002. Effects of Aronia melanocarpa juice as part of the dietary regimen in patients with diabetes mellitus. Folia Medica, 44: 20-23.

Slimestad, R., K. Torskangerpoll, H. S. Nateland, T. Johannessen \& N. H. Giske, 2005, Flavonoids from black chokeberries, Aronia melanocarpa. Journal of Food Composition and Analysis, 18: 61-68.

Surh, Y. J., 2003. Cancer chemoprevention with dietary phytochemicals. Nature Reviews Cancer, 3: 768-780.

Takahashi, K. H. \& W. U. Blanckenhorn, 2015. Effect of genomic deficiencies on sexual size dimorphism through modification of developmental time in Drosophila melanogaster. Heredity, 115: 140-145.

Testa, N. D., S. M. Ghosh \& A. W. Shingleton, 2013. Sex-specific weight loss mediates sexual size dimorphism in Drosophila melanogaster. PLoS ONE, 8: e58936.

Tomić, M., Đ. Ignjatović, G. Tovilović-Kovačević, D. Krstić-Milošević, S. Ranković, T. Popović \& M. Glibetić, 2016. Reduction of anxiety-like and depression-like behaviors in rats after one month of drinking Aronia melanocarpa berry juice. Food and Function, 7: 3111-3120.

Trajković, J., S. Pavković-Lučić \& T. Savić, 2013. Mating success and wing morphometry in Drosophila melanogaster after long-term rearing on different diets. Behaviour, 150: 1431-1448.

Trotta, V., S. Cavicchi, D. Guerra, H. Ditte, D. H. Andersen, G. A. Babbitt, N. K. Torsten, K. S. Pedersen, V. Loeschcke \& C. Pertoldi, 2011. Allometric and non-allometric consequences of inbreeding on Drosophila melanogaster wings. Biological Journal of the Linnean Society, 102: 626-634.

Valcheva-Kuzmanova, S., P. Borisova, B. Galunska, I. Krasnaliev \& A. Belcheva, 2004. Hepatoprotective effect of the natural fruit juice from Aronia melanocarpa on carbon tetrachloride-induced acute liver damage in rats. Experimental and Toxicologic Pathology, 56: 195-201.

Valcheva-Kuzmanova, S., K. Kuzmanov, S. Tancheva \& A. Belcheva, 2007. Hypoglycemic effects of Aronia melanocarpa fruit juice in streptozotocin-induced diabetic rats. Methods and Findings in Experimental and Clinical Pharmacology, 29: 101-105.

Valcheva-Kuzmanova, S., K. Marazova, I. Krasnaliev, B. Galunska, P. Borisova \& A. Belcheva, 2005. Effect of Aronia melanocarpa fruit juice on indomethacin-induced gastric mucosal damage and oxidative stress in rats. Experimental and Toxicologic Pathology, 56: 385-392.

Valcheva-Kuzmanova, S. \& M. Zhelyazkova-Savova, 2009. Anxiolytic-like effect of Aronia melanocarpa fruit juice in rats. Methods and Findings in Experimental and Clinical Pharmacology, 31: 651-654.

Zafra-Stone, S., T. Yasmin, M. Bagchi, A. Chatterjee, J. A. Vinson \& D. Bagchi, 2007. Berry anthocyanins as novel antioxidants in human health and disease prevention. Molecular Nutrition and Food Research, 51: 675-683.

Zar, J. H., 1999. Biostatistical Analysis. 4th Ed. Prentice Hall, New Jersey, 469 pp. 